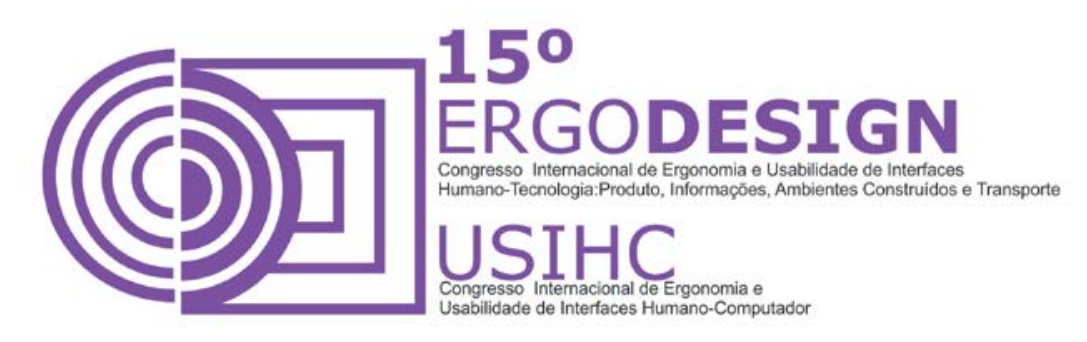

\title{
ERGONOMIA E AGRICULTURA: PROPOSTA DE REDESIGN PARA UM PULVERIZADOR AGRÍCOLA
}

\author{
GONÇALVES, John (1) \\ GOUVEIA, Taiane (2) \\ BARROS, Bruno (3) \\ (1) Universidade Federal de Pernambuco, Bacharel \\ e-mail:johndesigner@outlook.com \\ (2) Universidade Federal de Pernambuco, Bacharel \\ e-mail:Taianegouveiaals@hotmail.com \\ (2) Universidade Federal de Pernambuco, Mestre \\ e-mail: barros bruno@hotmail.com
}

\begin{abstract}
RESUMO
Segundo a CNA (Confederação da Agricultura e Pecuária do Brasil), a agropecuária representa no PIB $23 \%$, batendo 1 trilhão de reais, com esse crescimento o número de pequenos e médios agricultores cresceu, por não terem condições de comprar equipamentos modernos, fazem utilização de equipamentos que podem causar lesões nos funcionários, a falta de instrução na utilização correta causando intoxicações e lesões. Utilizando da metodologia de Intervenção Ergonomizadora do Sistema Humano-Tarefa-Máquina (SHTM), foi analisado, identificado problemas no uso do pulverizador agrícola do IFPE Belo Jardim, e com os dados encontrados propor melhorias para o equipamento, favorecendo o bem estar dos trabalhadores.
\end{abstract}

\section{ABSTRACT}

According to the CNA (National Confederation of Agriculture and Livestock of Brazil), agriculture in GDP is $23 \%$, hitting one trillion dollars, with this growth the number of small and medium farmers grew, for not afford modern equipment, make use equipment that can cause injury to employees, lack of education on the proper use causing poisoning and injuries. Using the Ergonomizadora Intervention methodology Human Task-Machine System (SHTM), were analyzed, identified problems in the use of agricultural spray OPSI Belo Jardim, and the data found propose improvements to the equipment, promoting the welfare of workers. 


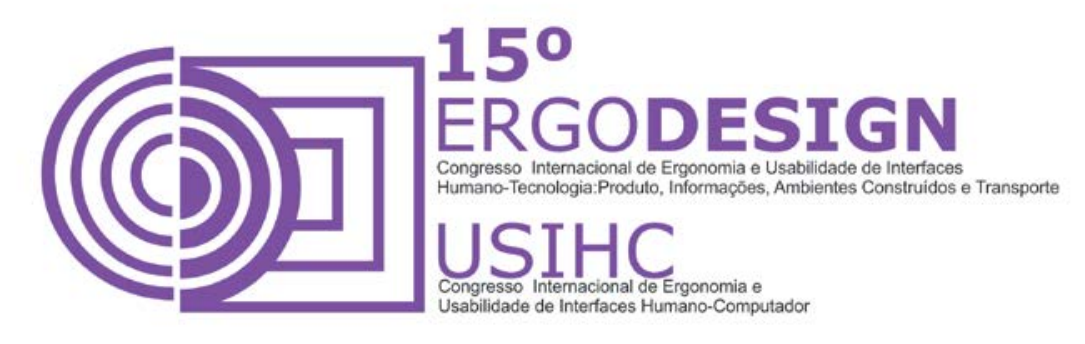

\section{INTRODUÇÃO}

Para a corrente pesquisa, foi selecionado o pulverizador Jacto Costal XP de $20 \mathrm{~L}$, no qual foi detectado problemas no manuseio e na fabricação, tendo como objetivo analisar seus materiais, tamanhos e pegas, no intuito do desenvolvimento e correções projetais do mesmo.

Com base nos conceitos antropométricos e biomecânicos ocupacionais, foi possível identificar os limites do ser humano. A obtenção das dimensões e proporções físicas do corpo humano, e foram feitas através de métodos e tabelas confiáveis, cuja aplicação facilita a adequação dos produtos a seus usuários. A interação física entre o trabalhador e seu instrumento de trabalho, no caso deste funcionário, seu trabalho pode ser classificado como trabalho estático, através os movimentos realizados no horário comercial. A apreciação ergonômica é uma fase exploratória que compreende o mapeamento dos problemas ergonômicos, efetuando observações e entrevistas nos locais de trabalho, registrando através de fotografias. E propondo através do redesign do produto alterações como o melhoramento dele como um todo.

\section{FUNDAMENTAÇÃO TEÓRICA}

\subsection{Identificação do produto}

O pulverizador Jacto Costal XP de $20 \mathrm{~L}$ é um produto padronizado por todo o país, tendo também variações de $12 \mathrm{~L}$ e $16 \mathrm{~L}$, voltado para área agrícola para aplicação de vermífugos, inseticidas, defensivos, fertilizantes em plantações evitando a proliferação de ervas daninhas e parasitas e ajudando as plantações a serem mais resistentes. Fabricado na cor azul com laranja, a parte azulada, o material é de plástico, já a parte laranja é de ferro, como podemos ver na (figura 1) logo abaixo. Também contém uma bomba para expelir o liquido que é de alumínio. Contém uma lança de onde o operador desse equipamento segura para direcionar o local onde vai ser colocado o produto, ainda na mesma temos o registro que regula a quantidade de produto que irá ser expelida possuí também uma cinta de nylon preta que irá ser presa ao funcionário que irá utilizar assim dando a ele mais firmeza no seu manuseio. Tem uma alavanca que serve para bombear a saída do produto, contém uma alça onde ajuda no transporte, possui uma tampa rosqueada por onde tem um orifício que é colocado os produtos.

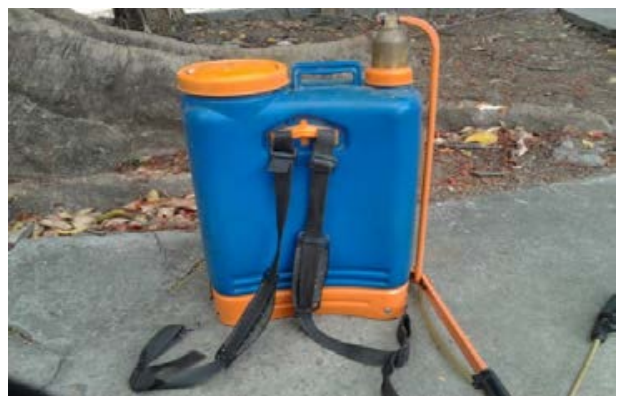

Figura 1 Pulverizador agrícola 


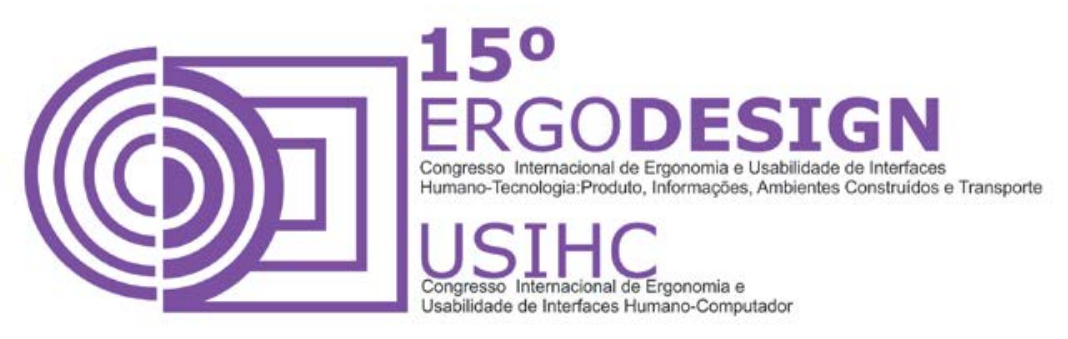

\subsection{Dados Antropométricos e Biomecânicos}

De acordo com Soares (2001), um produto portátil é aquele que o usuário possa conduzir confortavelmente por, pelo menos dez minutos sem se cansar. Devem-se levar em consideração alguns fatores que implicam na portabilidade de um produto, levando em consideração o uso do Pulverizador destacamos: peso, dimensões do produto, pega e material. Ainda de acordo com Soares (2001), um projeto de produtos portáveis deve respeitar algumas considerações:

- Evitar formas pontiagudas sobre a superfície que exijam a pega;

- Alças com textura para melhorar a superfície de fricção quando as mãos estiverem frias ou úmidas;

- Projetar o produto de forma que o punho esteja reto quando o produto está sendo seguro. Isto irá reduzir a distensão do punho;

- Alinhar a alça do produto com o plano de força. Considerar as forças de empurrar e puxar, assim como os torques;

- Dimensionar o diâmetro da alça de forma a adequação as exigências de força;

- Usar lados semi-inclinados sobre a superfície da pega ou alça para melhorar a precisão se exigido pela tarefa;

- Evitar acabamentos lisos para superfícies de produtos que devem ser seguros. Lembrando que a pega no design de produto portável seria o fator principal a ser projetado, visando a adequação e seu desempenho, deve-se considerar também essas medidas ergonômicas.

Comprimento mínimo: 100 mm; Diâmetro para a pega de força: 3-5 mm; Diâmetro para a pega de precisão: 8-16 mm; Abertura em torno da pega sem uso de luvas: $30-50 \mathrm{~mm}$.

De acordo lida (2005), o trabalho estático é aquele que exige uma contração contínua dos grupos musculares que estão sendo contraídos, para manter uma determinada posição. O autor alerta que um trabalho estático com aplicação de $50 \%$ da força máxima pode durar no máximo 1 minuto, enquanto que aplicações com menos de $20 \%$ da força máxima permitem manter as contrações musculares por mais tempo e que após ultrapassar os 15\% da capacidade máxima de desempenho da musculatura humana, deverá haver pausas para recuperação dessa musculatura e com isso o trabalhador continuar desenvolver sua atividade.

No uso diário, do pulverizador por um longo tempo ele irá causar DORT'S. A sigla DORTs dignifica Distúrbios Osteomusculares Relacionados ao Trabalho, segundo (Hales e Bernand,1996) as DORTs são distúrbios dos tecidos moles e suas estruturas ao redor (Músculos, ligamentos, nervos e tendões), incluindo também a LER Lesões por esforço repetitivo e LTC Lesões por traumas cumulativos. De acordo com dados do Instituto Nacional de Prevenção às LER/DORT'S. (http:/www2.uol.com.br/prevler/), estas são a segunda causa de afastamento do trabalho no Brasil. São causadas por esforço repetitivos onde não há pausas para descaço, má postura ao exercer uma determinada função, excesso de carga, ficar em uma mesma posição durante um longo período de tempo. 


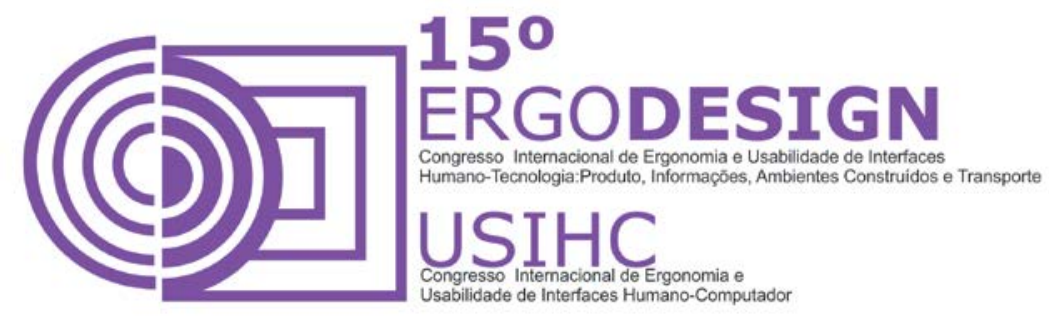

Alguns tipos de DORT'S: Tendinite (Tendões), Epicondilite (Cotovelo), Sinosivite (Bainhas sinoviais), Bursite (Bursas articulares), Miosite, Síndrome do Túnel de Carpo, Síndrome do ombro doloroso entre outras.

\section{QUADRO DE PROBLEMAS, CAUSAS, SINTOMAS E SOLUÇÃO ERGONÔMICA}

Problemas: Cotovelo de atleta (Epicondilite)

Causas: Stress repetido. Ruptura do tendão do cotovelo.

Sintomas: Dor do cotovelo ao antebraço e ao movimentar o cotovelo.

Solução Ergonômica: Reduzir a pega de força.

Problemas: Bursite

Causas: Inflamação do burso devido ao enrijecimento dos tendões causado pelo esforço sem recuperação.

Sintomas: Dor nas articulações

Solução Ergonômica: Evitar posições erradas, diminuição da carga exercida pelo membro superior.

Problemas: Bolhas e Calosidades

Causas: Atrito constante, pressão em um ponto.

Sintomas: Formação de liquido subcutâneo, ou camadas densas e secas na palma da mão.

Solução Ergonômica: Diminuir o atrito, entre a palma da mão e a pega com o aumento da tração.

\section{PROCEDIMENTOS METODOLÓGICOS ADOTADOS}

A Metodologia selecionada para o desenvolvimento do estudo foi a Metodologia de Intervenção Ergonomizadora do Sistema Humano - Tarefa - Máquina, desenvolvida por Moraes e Mont'Alvão (2002), essa metodologia é subdividida em grandes etapas. De acordo com os autores, a apreciação Ergonômica é a primeira delas, as quais ressaltam que: A apreciação ergonômica é uma fase exploratória que compreende o mapeamento dos problemas ergonômicos da empresa. Consiste na sistematização do sistema humano-tarefa-máquina e na delimitação dos problemas ergonômicos-posturais, informacionais, acionais, cognitivos, comunicacionais, interacionais, deslocacionais, movimentacionais, operacionais, espaciais, 


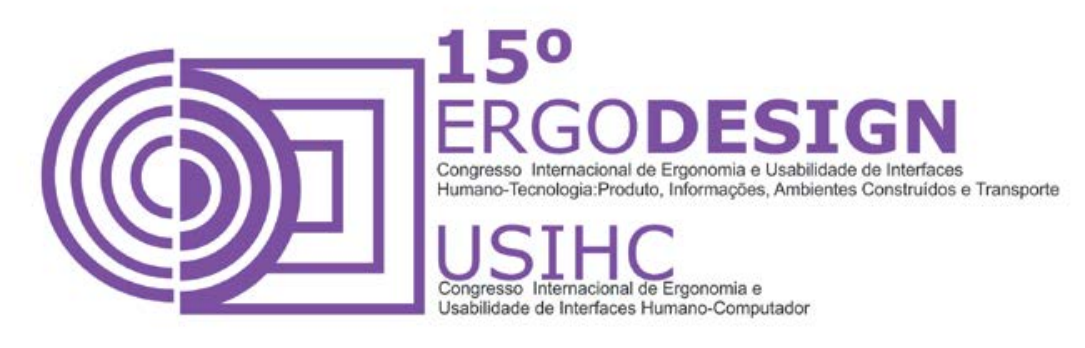

físico-ambientais. São efetuadas, no local de trabalho, observações e entrevistas com supervisores e trabalhadores. Realizam-se registros fotográficos e em vídeo.

\subsection{Apreciação ergonômica}

A apreciação ergonômica é uma fase de mapeamento dos problemas ergonômicos da empresa. Nesta fase é feita a sistematização do sistema humano-tarefa-máquina e a delimitação dos problemas. Esta fase é de observações, entrevistas e registros dos operadores no seu local de trabalho, e termina com o parecer ergonômico, que é a apresentação ilustrada dos problemas e disfunções do sistema humano-tarefa-máquina.

\section{Organografia das seções do IFPE}

\section{Início}

\begin{tabular}{|l|l|}
$\begin{array}{l}\text { Chegada ao trabalho de } \\
\text { moto } \\
\text { Troca-se de roupa } \\
\text { E vestem-se os EPI }\end{array}$ & $\begin{array}{l}\text { Verifica se o equipamento } \\
\text { está bom para uso } \\
\text { Enche o equipamento com o } \\
\text { produto a ser usado no local } \\
\text { Leva o equipamento para o } \\
\text { local certo }\end{array}$ \\
\hline
\end{tabular}

Coloca-se o equipamento nas costas e começa a esborrifar 0 produto

E assim vai se deslocando até acabar o produto ou terminar de pulverizar todo o local

\section{Descrição da mão de obra}

\section{a. Caracterização da mão de obra}

Para poder exercer as atividades com o pulverizador, não é necessário o funcionário ter o ensino médio completo ele deve possuir uma experiência com produto. $O$ instituto não possibilita aos funcionários receberem auxilio transporte ou moradia, nem assistências médica ou odontológica.

Foi visto que o IFPE possui um fichário para monitorando entradas e saídas dos funcionários contendo também horários e presença, onde se acontecer de haver faltas ou atrasos, no caso de não possuir atestado médico o mesmo poderá ser penalizado com descontos salariais ou haverá de pagar com horas extras.

O IFPE para atender as necessidades dos funcionários possui um banheiro em cada setor, e disponibiliza refeitório para seus funcionários. 


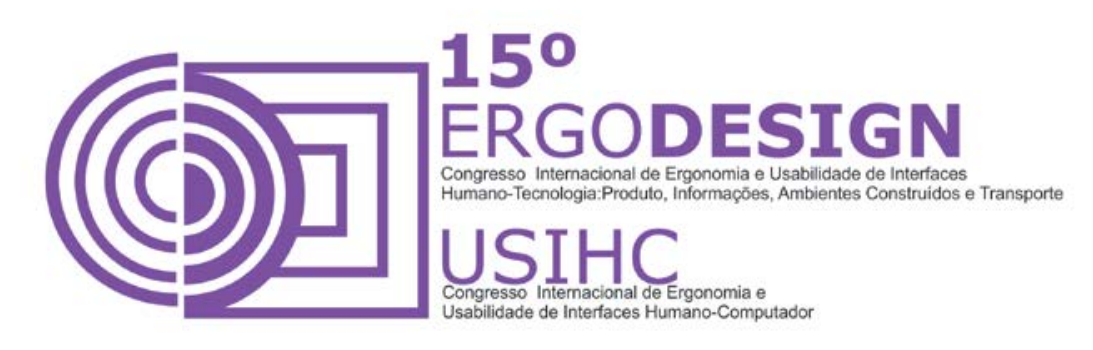

\section{Sistematização do sistema Humano-Máquina}

\section{a. Caracterização e posição serial do sistema}

O quadro abaixa representará a posição do serial do sistema- alvo que é o pulverizador, para a compreensão das relações entre o sistema- alvo em questão.

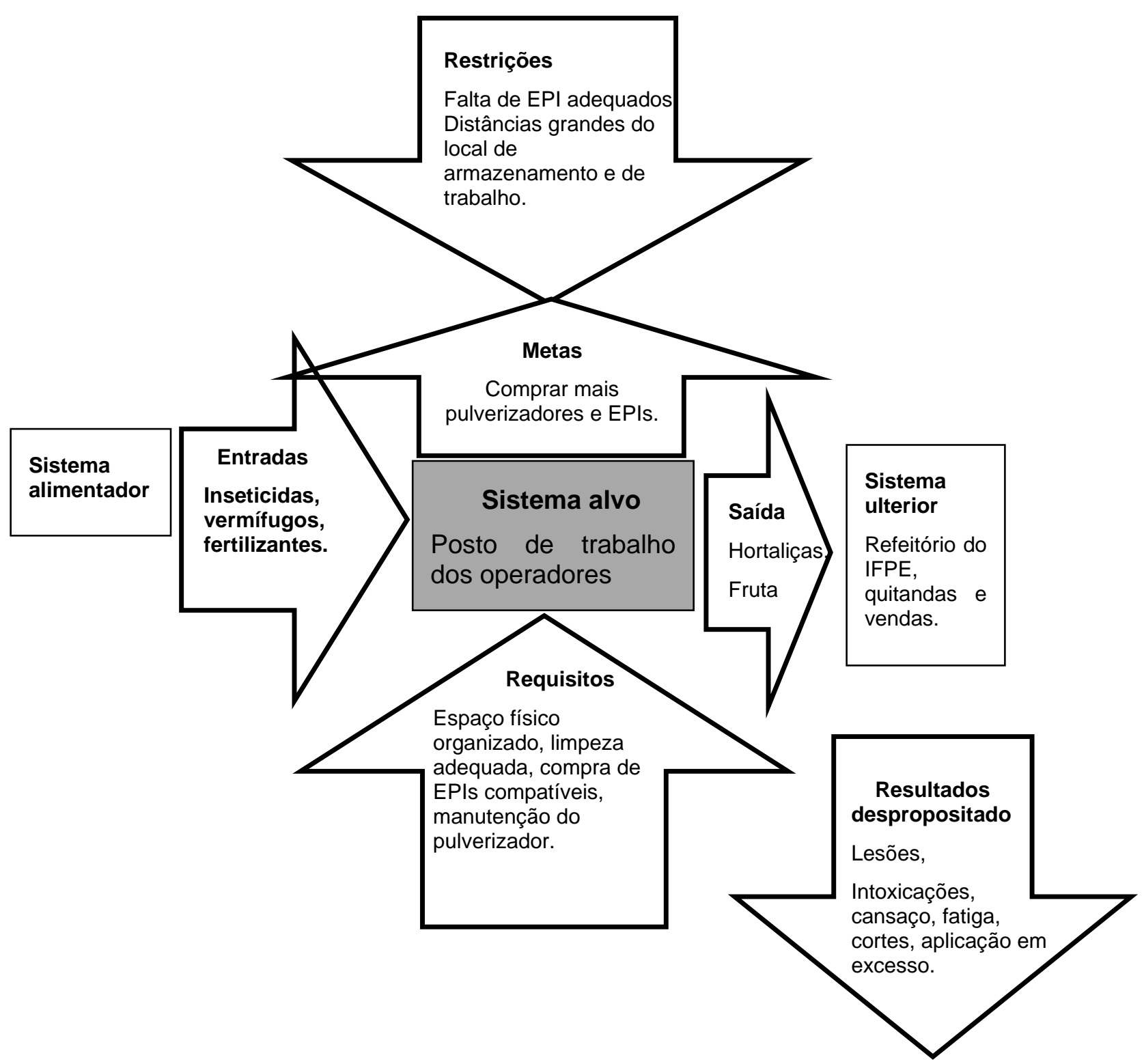




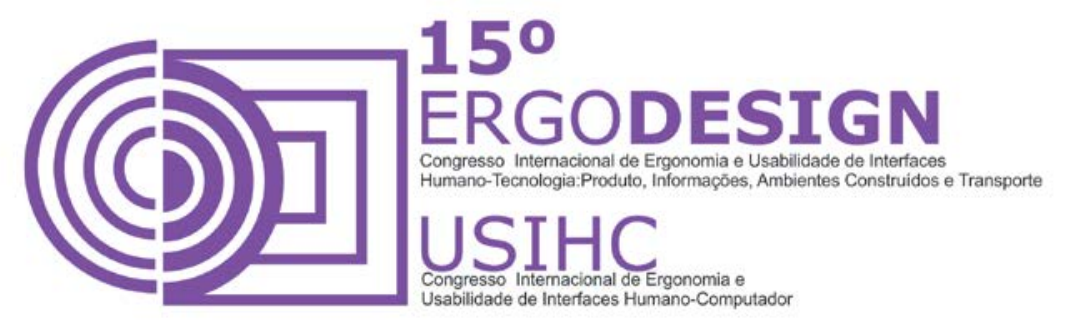

\subsection{Modelagem Comunicacional Do Sistema}

No quadro abaixo apresenta as sequencias das funções/ operações e as decisões implicadas que compreendem os sentidos humanos envolvidos, ações realizadas, deslocamentos, postura, informações que a máquina fornece para o ser humano processar.

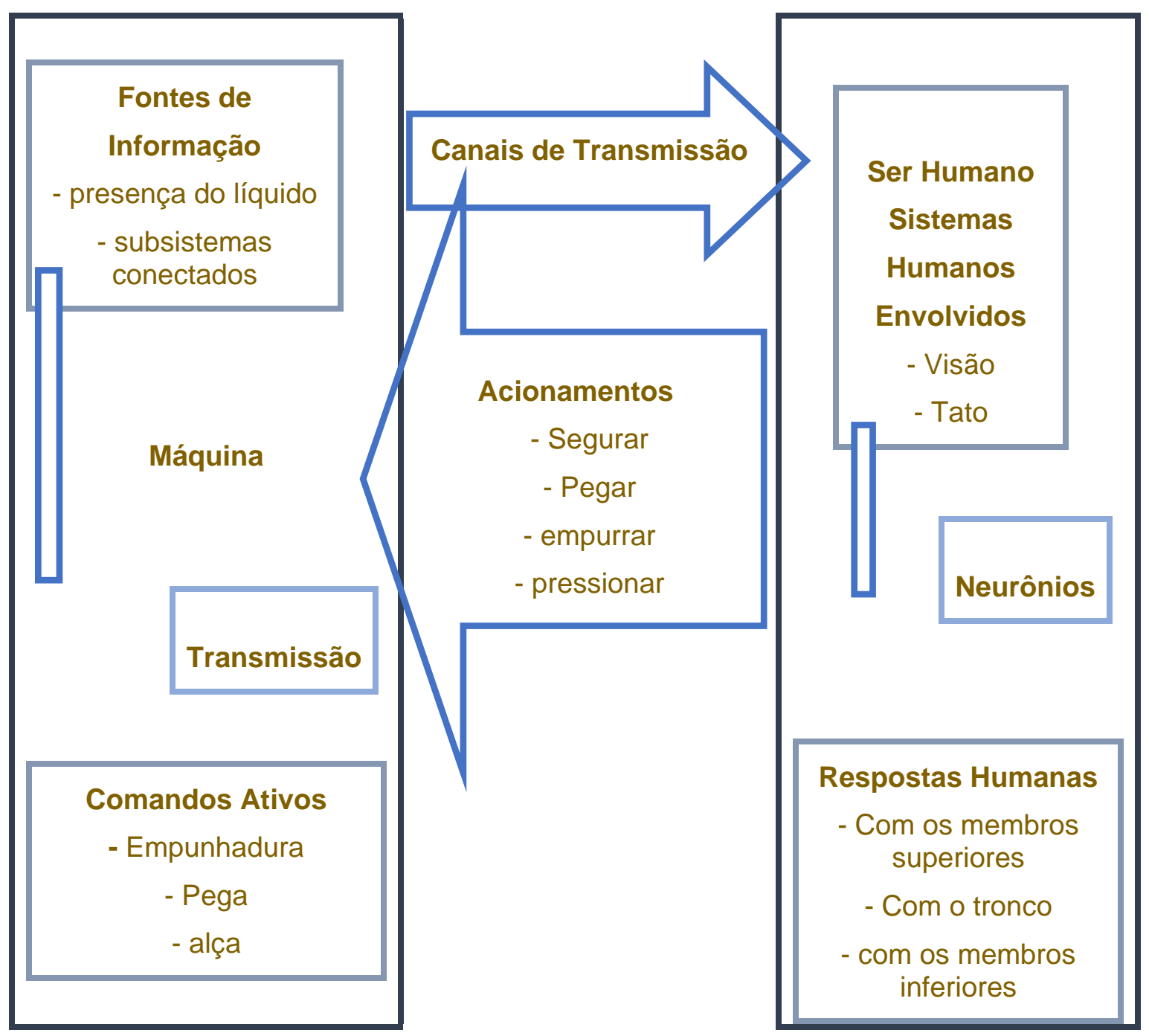




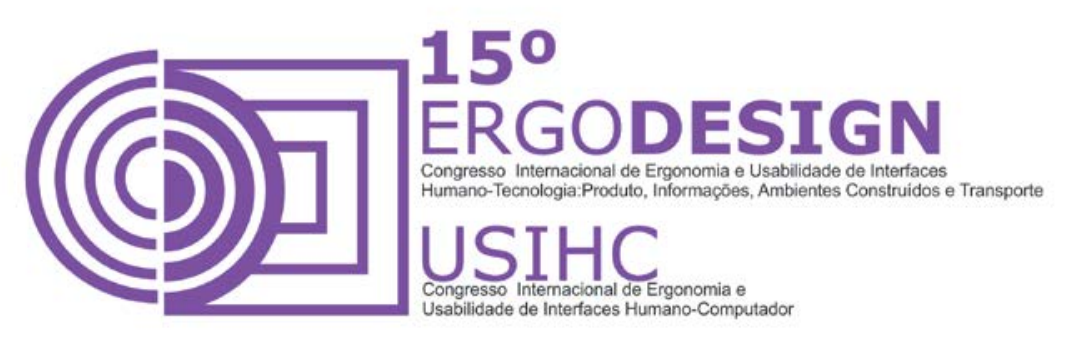

\subsection{Aplicação De Questionário}

Foi necessária a realização de um questionário aos entrevistados, para a elaboração deste trabalho, perguntas no que diz respeito sobre qual o Tempo que estão trabalhando na empresa, qual é o estado civil de cada um deles, se estes são destros ou canhotos e se eles moram na mesma cidade onde trabalham. Quanto tempo eles passam para chegar ao trabalho e de que forma é que eles chegam lá e o que achavam do ambiente de trabalho em que atuam. Também questionamos sobre as condições físicas, para que este nos informasse se haveria dores musculares, irritações, lesões, fadiga e cansaço, última vez que eles adoeceram se normalmente costumam tomar algum tipo de medicamento para aliviar esses problemas de lesões e fadigas. Em que partes do corpo incomodavam mais e em que quantidade de tempo que isso ocorria ao carregar o pulverizador. Pedimos que descrevesse sobre as sensações como acordar cansado, com dores ou ficar irritado.

\subsection{Aplicação da Escala de Corllet}

No intuito de complementar a fase exploratória de avaliação física dos usuários, tornou-se necessária a aplicação da Escala de desconforto Postural de Corllet. Para IIDA (2004) a escala de Corllet pode ser caracterizada como:

A Principal vantagem desse diagrama é seu fácil entendimento. Ele pode ser distribuído em grande quantidade, juntamente com algumas instruções simples, para auto preenchimento dos trabalhadores. Naturalmente, haverá diferenças entre critérios individuais de preenchimento, mas serve para se fazer um mapeamento geral de toda a empresa. Assim, podem-se identificar as máquinas, equipamentos e locais de trabalho que apresentam maior gravidade (acima do $3^{\circ}$ nível) e que mereçam atenção imediata. Com isso, o esforço dos analistas pode ser dirigido para aqueles pontos prioritários, conseguindo-se resultados mais significativos

(Itirolida- Ergonomia, projeto e produção).

\section{RESULTADOS}

\subsection{Questionário}

Para nosso projeto foram entrevistados três pessoas, com idades variando de 21 a 52 anos. Possuindo uma média de peso é entre 57 a $65 \mathrm{~kg}$, e estatura de 1,63 a 1,67m. Dois dos três entrevistados identificaram como casados e apenas um no momento da entrevista se encontrava solteiro, onde todos são do sexo masculino e todos também são destros.

Estes são moradores da cidade de Belo Jardim trabalham no IFPE da cidade. Dois dos três entrevistados estão trabalhando nesse emprego há 8 anos e 1 deles trabalha apenas há dois anos, tendo uma jornada de trabalho de 8 horas diárias com o pulverizador. 


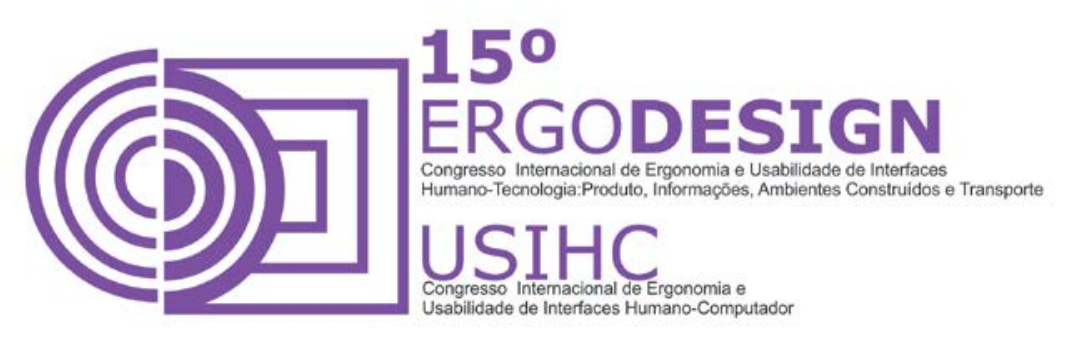

\subsection{Mapa de Desconforto Postural Corllet}

Este mapeamento consiste na avaliação das dores causadas pelo período de trabalho exercido com a utilização do pulverizador. O questionamento foi aplicado a 3 (três) funcionários em 3 (três) horários distintos. A primeira aplicação foi ás 7:00 (sete) horas da manhã, antes do início das atividades proporcionando a avaliação em repouso e as dores resultantes das atividades presentes exercidas onde houve a existência de algumas dores nas mãos, nos ombros e nas costas. A segunda aplicação iniciou-se ás 10:00 (dez) horas da manhã onde os entrevistados após fazerem uso do pulverizador se queixaram dores de nível moderado nas regiões dos membros superiores e inferiores, nuca, nas costas. A terceira avaliação iniciou-se ás 17(dezessete) horas da tarde que é o horário de finalização da jornada de trabalho visto que é um longo período se tratando de um produto pesado que requeira bastante energia dos entrevistados.

\subsection{Problematização Ergonômica}

Através da análise visual foi percebido que ao utilizar o pulverizador, no período de 8 horas diárias o funcionário sofre lesões ocasionadas pela falta de proteção, não existente na máquina. Com relação ao peso em conjunto com o material usado nas alças que proporcionam o transporte do e equipamento que não é adequado, causando lesão por abrasão. Se tratando da pega, por a mesma não ser adequada causando desvio ulnar. Quanto ao contato do produto com as costas, por não ter proteção também causa lesão por abrasão. Ao exercer pressão e movimento repetitivo ao acionar a alavanca, pode gerar problemas como epicondilite e bursite. Foram detectados problemas acionais nas empunhaduras e ângulos de pegas, movimentacionais alta movimentação, interfaciais com posturas inadequadas e operacional por conta do ritmo intenso.

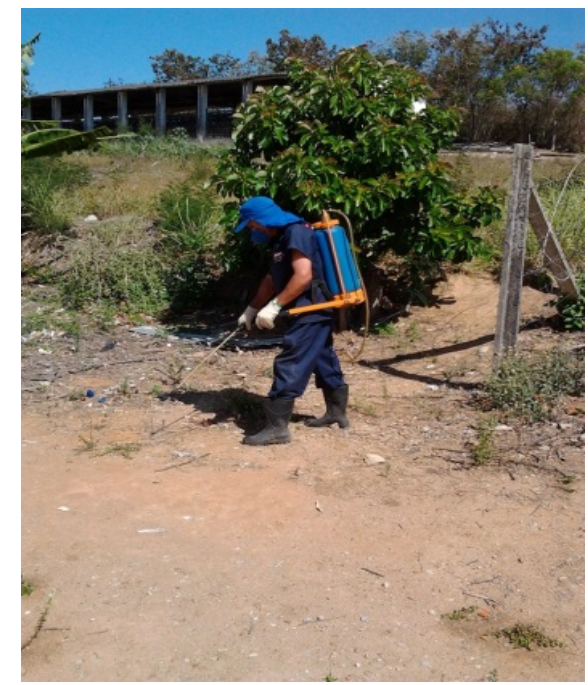

Figura 3 operador utilizando o equipamento 


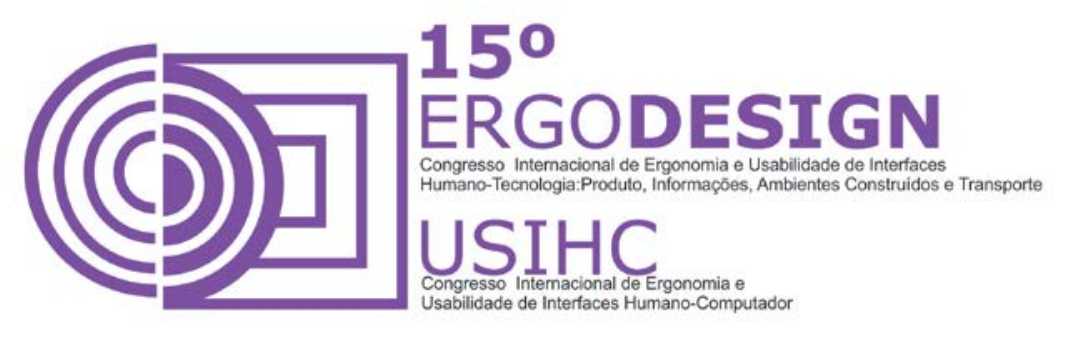

\subsection{Lista de recomendações ergonômicas:}

Melhoramento da pega da alavanca; Substituição do material da cinta, de nylon para poliéster; Acréscimo de uma cinta na base do equipamento; Acolchoamento da parte posterior do produto; Centralização da alça; Redução da área de movimento da alavanca; Reposicionamento da cinta (alças); Troca do materialda base e da alavanca de ferro para alumínio; Alteração do formato da alavanca retirando as quinas; Troca do material da bomba de alumínio para plástico.

\section{ETAPAS DE CRIAÇÃO DO PRODUTO}

Tendo em vista os problemas estudados quanto ao pulverizador as principais mudanças no produto serão as trocas de materiais pesados por material mais leve, e inclusão de produtos que amorteçam o impacto do peso do pulverizador nas costas e nos ombros dos usuários como também o angulo e o material da pega.

Diminuir o tamanho da tampa para poder localizar melhor as alças do produto para o balanceamento do peso do mesmo e inserir uma cinta na base do equipamento que fique presa ao tronco do trabalhador proporcionando divisão de peso sobre o corpo do mesmo e aumento e mudança na forma da alavanca também.

\subsection{Material}

Dos vários modelos existentes de pulverizador, todos possuem o tanque de plástico Worker, pois é considerado ideal por ser um material leve, sendo um plástico bastante resistente para suportar o peso do líquido, também é resistente as altas temperaturas solares e aos produtos químicos que é inserido no tanque do mesmo. A base dele é composta de ferro tornando o objeto ainda mais pesado. A cinta no trabalho é feita de nylon trazendo desconforto ao trabalhados por ser um material sem acolchoado.

\section{DISCUSSÃO E APRESENTAÇÃO DOS RESULTADOS:}

\subsection{Proposta de Redesign}

O pulverizador que propomos terá a lança que o operário segura ela será de Inox para evitar oxidação e a alavanca terá uma inclinação de $45^{\circ}$ para que a pega se adeque a pega da mão e facilite o manuseio. Alavanca será maior para que braços maiores possam trabalhar sem esforços, e o operador exerça uma força menor na alavanca. Na parte de frente do tanque será inserido silicone para proporcionar conforto ao trabalhador. A bomba que é de alumínio irá mudar para plástico para que o produto fique ainda mais leve e diminuindo também sua dimensão. O material da cinta de trabalho será também substituído por poliéster por ser material mais macio. Colocaremos uma cinta fixa na base do tanque para que seja presa na cintura, proporcionando uma maior fixação no tronco do usuário. 


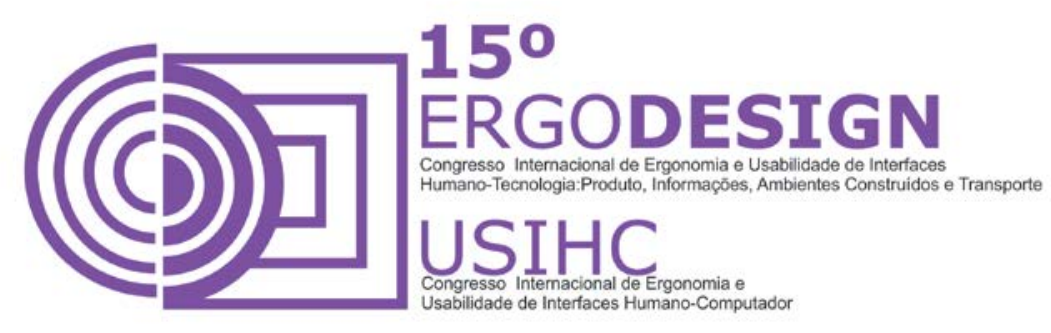

\subsection{Desenho Em Cotas}

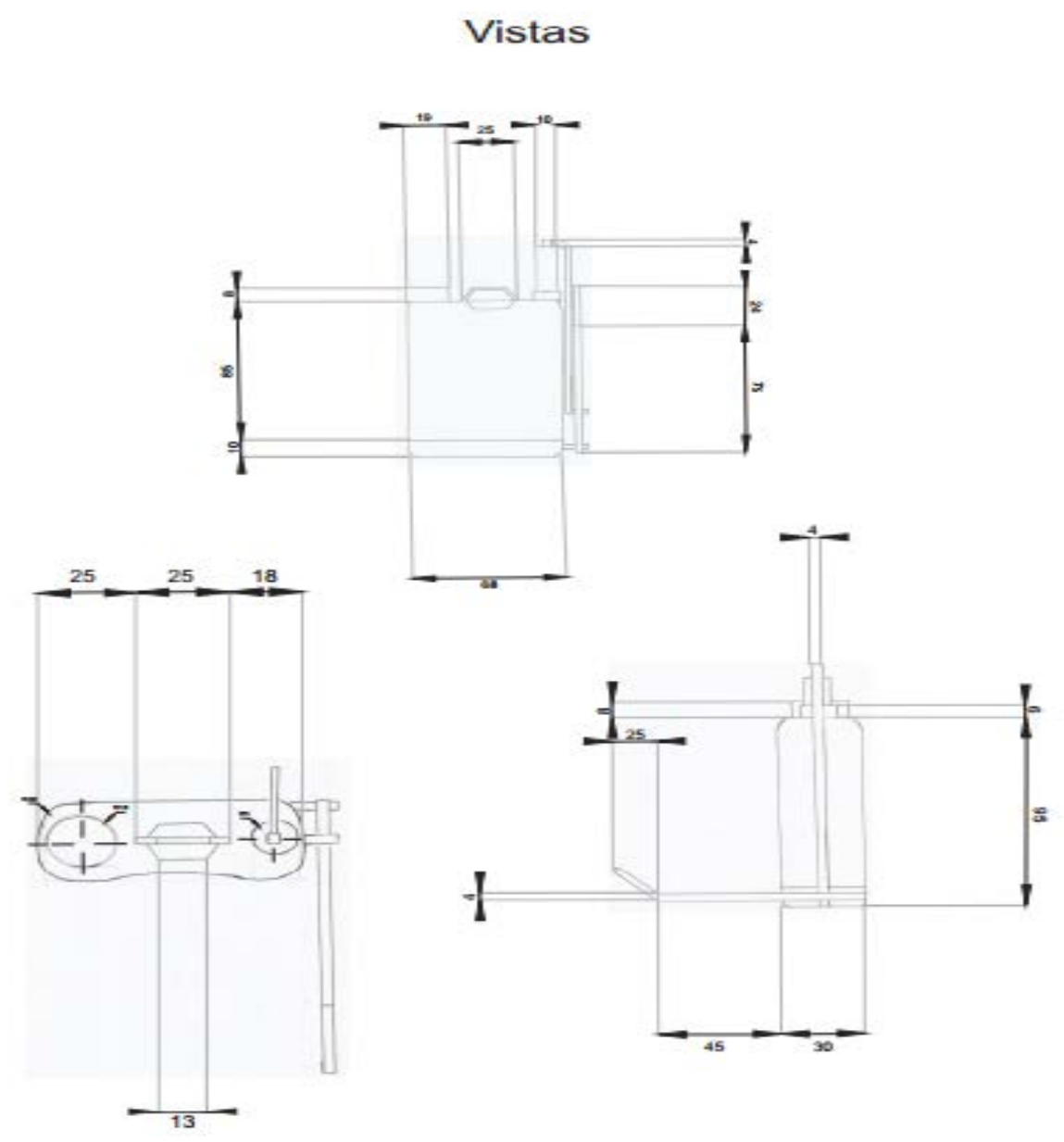

Figura 4 vista lateral, superior e frontal 


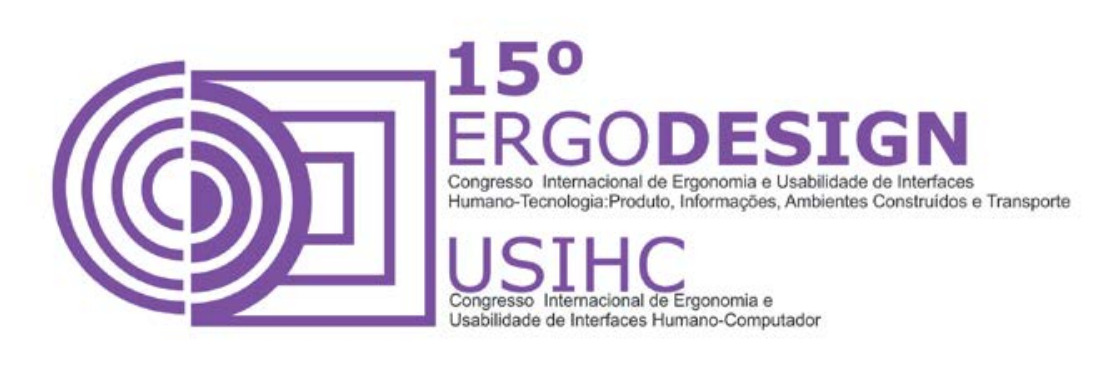

\subsection{Rendering Do Pulverizador}

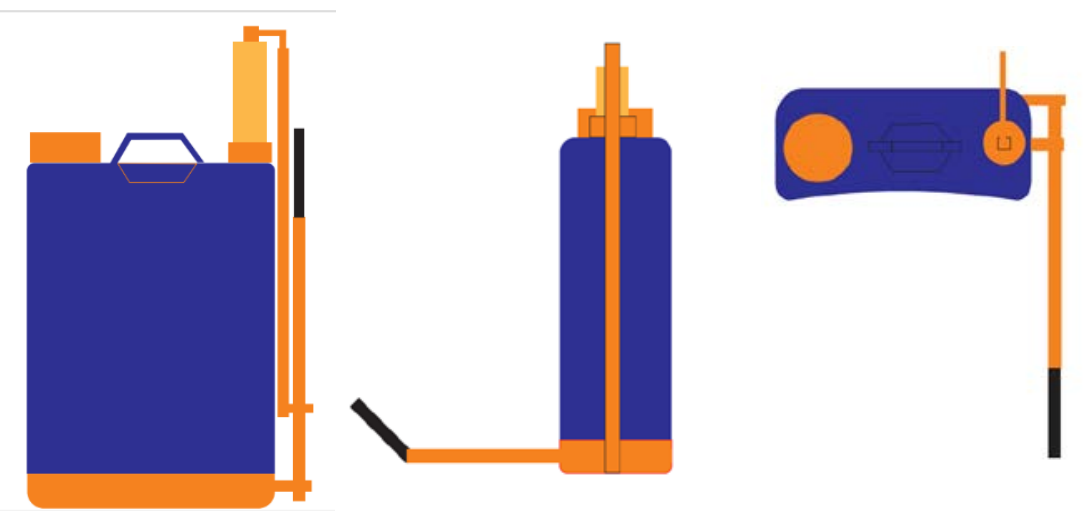

Figura 5 rendering com as modificações

\section{CONCLUSÕES E CONSIDERAÇÕES FINAIS:}

Depois de várias análises feitas, foi concluído que o pulverizador de 20 litros tem que passar principalmente por mudanças no tamanho de certas partes do produto como o aumento e mudança do formato da alavanca, também na troca de materiais pesados por mais leves (a troca do ferro da base pelo alumínio) e inserindo uma cinta proporcionando maior coerência entre o objeto e o tronco do trabalhador.

O tanque, que é produzido em plástico Worker, e não possuem algo que diminua o contato entre o tanque e as costas do trabalhador que por sua resistência deverá ser inserido o silicone para amenizar esse impacto, assim também com as alças para que produzida adequando para que suportar o peso do tanque.

Diminuindo a tampa do tanque para melhor localizar as alças do produto, de maneira que o peso do mesmo de maneira que facilite o manuseio e a pega do pulverizador.

\section{REFERÊNCIAS BIBLIOGRÁFICAS}

IIDA. Itiro. Ergonomia projeto e produção. $2^{a}$ edição revista e ampliada. São Paulo: Blucher, 2005.

Ler/DORT cuidados para a sua saúde. Disponível em <http://www.lerdort.com.br>Acesso em 24 de maio. 2012.

FILHO. João Gomes. Ergonomia do objeto: sistema técnico de leitura ergonômica.

DUL. Jan. Ergonomia prática 1954. Editora Blucher $2^{\circ}$ edição, tradutor Itiro lida 2004. 